\title{
EFFECTS OF CIRCADIAN RHYTHM ON BALANCE PERFORMANCE
}

\author{
OSMAN KARAGUL1, GULBIN RUDARLI NALCAKAN², YELIZ DOGRU³, MURAT TAS 4 \\ ${ }^{1}$ Celal Bayar University, Institute of Health Sciences, Movement and Training Sciences, \\ Masters Programme, Izmir, Turkey \\ ${ }^{2}$ Ege University, Faculty of Sport Sciences, Department of Coaching Education, Izmir, Turkey \\ ${ }^{3}$ Ege University, Institute of Health Sciences, Sport and Health Sciences, Doctoral Programme, Izmir, Turkey \\ ${ }^{4}$ Celal Bayar University, School of Physical Education and Sport, \\ Department of Coaching Education, Izmir, Turkey
}

\author{
Mailing address: Gulbin Rudarli Nalcakan, Ege University, Faculty of Sport Sciences, Department of Coaching \\ Education, Gençlik Caddesi 35040 Bornova, Izmir, Turkey, tel.: +90 232 3425714, fax: +90 2323399000 , \\ e-mail: gulbinrn@gmail.com
}

\begin{abstract}
Introduction. The aim of the study was to examine the effect of circadian rhythm on dynamic balance performance and to determine the role of physical activity level, body temperature, chronotype, and gender in this possible effect. Material and methods. Forty-two young male and female subjects with different physical activity levels participated in the study. A dynamic equilibrium test, a Star Excursion Balance Test (SEBT), was conducted at 9:00, 13:00, and 17:00 on three different days with at least two days of interval between tests. The test scores were calculated by dividing the reaching distances by the leg length and multiplying the quotient by 100 . The physical activity level and sleep state were evaluated using questionnaires. Before each test, body temperatures were measured orally. Results. The best SEBT scores were found at 13:00 and 17:00 in the male group and in the trained group. The body temperature changes increased parallel to SEBT scores. The scores for the non-dominant leg were found to be significantly different in posterior test directions, and those for the dominant leg were different in anterior directions. Chronotype did not affect the test results. Conclusions. Circadian rhythm was found to have an effect on dynamic balance performance. Body temperature, gender, and physical activity level were also found to play a role in this effect.
\end{abstract}

Key words: dynamic balance, postural control, circadian rhythm, star excursion balance test

\section{Introduction}

Balance ability is known to be important in a successful athletic performance, especially in starting, changing direction, finishing, maintaining certain body postures, and holding and moving an object [1]. Physiological stresses that occur during training or competitions prevent the optimum implementation of athletic abilities, and such stresses may lead to loss of balance, which might result in injury [2]. Besides, the ability to control the centre of gravity while passing from one movement to another during dynamic performances affects many features like movement force, speed, and hit rate [3].

Circadian rhythm refers to cyclical variations repeated at regular intervals in 24 hours [4]. Circadian rhythm has been found to affect athletic performance levels [5]: a difference of $5-7 \%$ was observed between the morning and evening (9:00 and 18:00) results of multiple jumping tests [6], peak isometric grip strength was observed between 14:00 and 19:00 [7], and power output on a swim bench peaked at 18:00 [8].

There are few studies on circadian rhythm effects on balance. Gribble and Hertel [9] claim dynamic balance performance in the morning is better than the afternoon and evening performance; Zouabi, Quarck, Martin, Grespinet, and Gauthier [10] observed no time-of-day effect on postural static and dynamic balance. Cagno et al. [11] claim that the static balance per- formance of rhythmic gymnasts does not change at any time of the day, but their dynamic balance performance reaches a peak in the morning. Complicated balance movements require more concentration and attention, and they are affected by sleep state [12]; moreover, the change in body temperature is one of the main factors affecting circadian rhythm [13].

Not all athletic rhythms reach a peak at the same time of the day. "Simple" tasks that are not very cognitively demanding tend to reach a peak in the evenings in parallel with the core temperature. However, "complicated" tasks involving a wider range of cognitive components tend to reach a peak in the morning and to show a significant decrease thereafter [11].

The objective of this study is to examine the daily change in dynamic balance and the role of physical activity level, body temperature, chronotype, and gender in this possible change. Our hypothesis is that in trained and male subjects, dynamic balance will lead to better results during all times except the morning in parallel to body temperatures.

\section{Material and methods}

\section{Subjects}

Forty-two healthy male and female subjects with different physical activity levels voluntarily participated in the study. The criteria for test subjects included being between 18 and 25 years 
old and very active, according to the International Physical Activity Questionnaire (IPAQ) for trained groups and inactive and/or mildly active according to the IPAQ for control groups. The disqualifying criteria included having any illnesses or injuries in the last 6 months that might affect balance performance or a failure to complete the test period. Two out of 44 subjects were disqualified, as they failed to complete the test period.

The subjects were informed of the procedures applicable in the study and associated risks, and all provided informed consent in writing. The experimental protocol was approved by the Local Scientific Research Ethics Board (Approval No.: 20.478.486-172).

\section{Study design}

Height and leg height were measured using standard methods [14]. Body composition was measured with the bioelectric impedance method using a body analyser (Tanita BC-418, USA). The participants reported their dominant legs [13]. Body temperature was measured with a calibrated digital oral clinical thermometer (accuracy: $0.1^{\circ} \mathrm{C}$, Microlife, Switzerland) [15]. Standard laboratory conditions were provided $\left(22-23^{\circ} \mathrm{C}\right.$ and $<60 \%$ humidity) during the tests.

The Turkish version of the "Last 7 days short form" from the IPAQ [16] was used to determine the physical activity level of participants as inactive, mildly active, or very active. The Horne and Ostberg self-assessment Morningness-Eveningness Questionnaire was administered the day before the first testing session to assess the chronotype of the participants [17]. A validity and reliability analysis of the Turkish version was conducted by Pündük, Gür, and Ercan [18]. The Turkish version of the Epworth Sleepiness Scale was additionally used to determine sleep quality [19].

The participants' dynamic balance performances were determined using the Star Excursion Balance Test (SEBT), whose validity and reliability has been proven [20] and which is widely used among young adults (aged 18-25 years) [9, 12].

\section{SEBT measurement}

The SEBT dynamic balance test zone was designed with 8 separate lines. The lines were $120 \mathrm{~cm}$ long, and they were marked starting from a common point at an angle of 45 degrees. The test was administered at 9:00, 13:00, and 17:00 randomly on three different days with a minimum interval of two days between tests.

Before each test, the participants did warm-up exercises. These included five-minute running and dynamic extension of the lower body parts.

During the test, the participants, with their hands on their waist, were asked to keep one of their legs fixed on the centre point and extend the other leg to the most distant point possible on a line, touch it softly with the tip of their foot, and bring their leg back to its initial position without losing their balance. The participants extended their legs to eight different clockwise directions in one trial, and three rounds with a 30-second interval were completed for each extremity. The average of these three reaching distances was recorded in $\mathrm{cm}$. These lines indicated the anterior, anteromedial, medial, posteromedial, posterior, posterolateral, lateral, and anterolateral directions [21].

The test scores were calculated by dividing the reaching distances by the leg length and multiplying these quotients by 100 [22].

To avoid a learning effect, each test was repeated at least three times before the testing period [23]. There was an interval of minimum two days between the tests to help the participants recover [15].

\section{Statistical analyses}

All statistical analyses were performed using SPSS (version 15.0) for Windows. The Shapiro-Wilk W test and Levene's test, respectively, showed that the data obtained met the assumptions of normality and homogeneity of variance. Leg and time were within-subject factors; sex, sleep state, and physical activity level were the between-subject factors in the present study. The main effects and the interaction effect of these factors on the dependent variables were assessed using a $2 \times 2 \times 3$ (factor between related groups $\times$ leg $\times$ time) three-factor mixed-design variance analysis (ANOVA). In the case of significant main effects, a one-factor repeated measures ANOVA with the LSD post-hoc procedure was performed to identify the source of the difference. A paired samples t-test was used for analysing leg
Right Leg Stance/Left Leg Reach

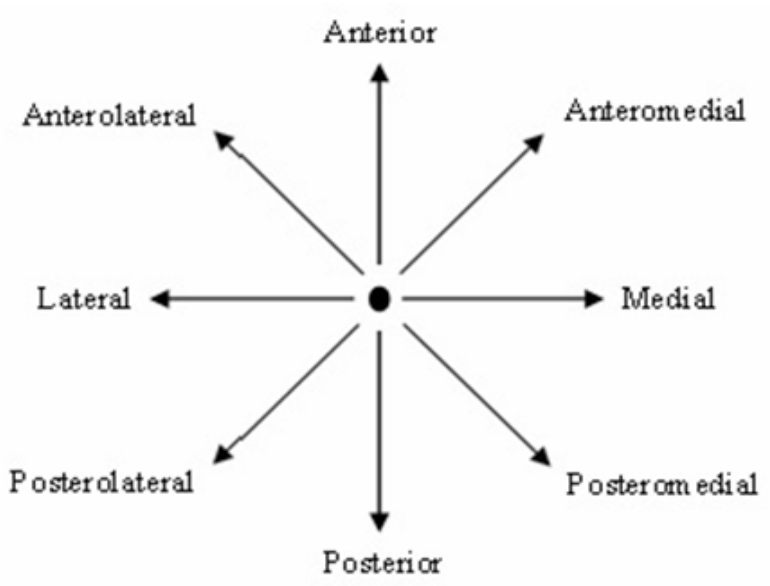

Left Leg Stance/Right Leg Reach

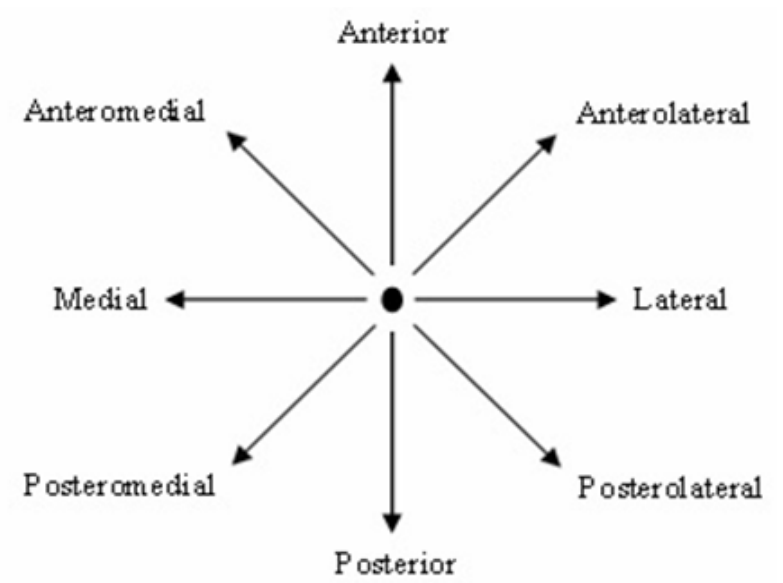

Figure 1. Star Excursion Balance Test right and left leg reaching directions 
differences, and an independent samples t-test was applied in analysing group differences with respect to sex and sleep state. A Pearson correlation coefficient test was used for correlation analysis between body temperature values and SEBT performances. The level of statistical significance was set at $\mathrm{p} \leq 0.05$. Effect sizes (ES) were determined using Cohen's $d$. The magnitude of the ES was classified as large $(\geq 0.80)$, moderate (0.50-0.79), small $(<0.20-0.49)$, or trivial (0-0.19).

\section{Results}

Certain physical features of all of the subjects and a comparison of the physical features of the trained and control groups are shown in Table 1 . Accordingly, there were statistically significant differences between the two groups in their age, body fat ratio, and body fat percentage parameters $(\mathrm{p} \leq 0.05)$.

Physical activity level, gender, and sleep state interaction in the time-dependent performance of the participants' $(n=$ 42) dominant or non-dominant legs were tested using variance analysis for all aspects of the test. Accordingly, the leg showed a different structure in the anteromedial direction $(\mathrm{F}=12.171$, $\mathrm{p}=0.001, \eta \mathrm{p} 2=0.264)$, in the medial direction $(\mathrm{F}=10.780$, $\mathrm{p}=0.002, \eta \mathrm{p} 2=0.241)$, in the lateral direction $(\mathrm{F}=12.667, \mathrm{p}=$ $0.001, \eta \mathrm{p} 2=0.271)$, and in anterolateral direction $(\mathrm{F}=15.474$, $\mathrm{p}=0.000, \eta \mathrm{p} 2=0.313)$. In opposition to this, time* physical activity level in the posteromedial direction $(\mathrm{F}=3.821, \mathrm{p}=0.027$, $\eta \mathrm{p} 2=0.101)$, time ${ }^{*}$ physical activity level in the posterolateral direction $(\mathrm{F}=3.274, \mathrm{p}=0.044, \eta \mathrm{p} 2=0.088)$, and the leg $(\mathrm{F}=$ 13.071, $\mathrm{p}=0.001, \eta \mathrm{p} 2=0.278)$ showed a different structure. In the posterior direction, time* physical activity level $(F=4.155$, $\mathrm{p}=0.020, \eta \mathrm{p} 2=0.109)$, time ${ }^{*}$ gender $(\mathrm{F}=3.695, \mathrm{p}=0.030$, $\eta \mathrm{p} 2=0.098)$, and the leg $(\mathrm{F}=4.722, \mathrm{p}=0.037, \eta \mathrm{p} 2=0.122)$ showed a different structure. Only in the anterior direction did time-dependent balance performance changes in the two legs show a similar structure in activity level, gender, and sleep state $(\mathrm{p}>0.05)$.

The scores obtained in the anterior, lateral, posterolateral, posterior, and posteromedial directions at 13:00 and in the ante-
Table 1. Physical features of all participants $(n=42)$ and comparison of trained $(n=27)$ and control $(n=15)$ groups

\begin{tabular}{|c|c|c|c|c|}
\hline & $\begin{array}{c}\text { Trained } \\
\text { group }\end{array}$ & $\begin{array}{c}\text { Control } \\
\text { group }\end{array}$ & ES (90\% Cl) & $\begin{array}{c}\text { Total } \\
\text { group }\end{array}$ \\
\hline $\begin{array}{c}\text { Age } \\
\text { (year) }\end{array}$ & $20.9 \pm 2.40^{* *}$ & $22.5 \pm 1.46$ & $-1.010(-2.87 /-0.87)$ & $21.5 \pm 2.24$ \\
\hline $\begin{array}{c}\text { Height } \\
\text { (cm) }\end{array}$ & $179 \pm 8.05^{* *}$ & $173 \pm 8.92$ & $0.141(-4.25 / 6.11)$ & $177 \pm 8.76$ \\
\hline $\begin{array}{c}\text { Body } \\
\text { mass } \\
\text { (kg) }\end{array}$ & $72.2 \pm 9.51$ & $70.9 \pm 15.8$ & $0.092(-9.81 / 3.92)$ & $71.7 \pm 12.0$ \\
\hline $\begin{array}{c}\text { BMI } \\
\text { (kg/ m })\end{array}$ & $22.6 \pm 2.41$ & $23.4 \pm 3.77$ & $-0.126(-3.01 / 0.93)$ & $22.9 \pm 2.95$ \\
\hline $\begin{array}{c}\text { Body fat } \\
\text { (\%) }\end{array}$ & $14.0 \pm 6.56^{* * *}$ & $22.8 \pm 8.20$ & $-0.967(-12.3 /-1.61)$ & $17.2 \pm 8.27$ \\
\hline $\begin{array}{c}\text { Body fat } \\
\text { (kg) }\end{array}$ & $10.3 \pm 5.2^{* *}$ & $16.0 \pm 6.67$ & $-1.212(-9.56 /-0.31)$ & $12.4 \pm 6.36$ \\
\hline $\begin{array}{c}\text { Leg } \\
\text { length } \\
\text { (cm) }\end{array}$ & $95.8 \pm 5.97$ & $93.0 \pm 7.19$ & $0.454(-5.03 / 3.91)$ & $94.8 \pm 6.48$ \\
\hline
\end{tabular}

$\mathrm{BMI}=$ Body Mass Index; $\mathrm{SD}=$ standard deviation; ${ }^{* *}=\mathrm{p} \leq 0.01$ and ${ }^{* *}=\mathrm{p} \leq 0.001$ show statistically significant differences between trained and control groups; ES = effect size; $\mathrm{CI}=$ confidence interval.

rior, posterolateral, and posterior directions at 17:00 ( $\mathrm{p} \leq 0.05)$ in the dominant leg were significantly different from those recorded at 9:00. When the legs were compared, the dominant leg was found to have a significantly higher performance in the anterolateral, lateral, and posterolateral directions, whereas the non-dominant leg had a significantly higher performance in the posterior, posteromedial, medial, and anteromedial directions (Tab. 2).

Table 2. Comparison of dominant and non-dominant leg SEBT scores ${ }^{¥}$ according to time of day

\begin{tabular}{|c|c|c|c|c|c|c|c|c|c|}
\hline \multirow{2}{*}{ SEBT directions } & \multicolumn{2}{|c|}{$9: 00$} & \multirow[b]{2}{*}{ ES } & \multicolumn{2}{|c|}{$13: 00$} & \multirow[b]{2}{*}{ ES } & \multicolumn{2}{|c|}{$17: 00$} & \multirow[b]{2}{*}{ ES } \\
\hline & Dominant & Non-dom. & & Dominant & Non-dom. & & Dominant & Non-dom. & \\
\hline Anterior & $84.8 \pm 8.13$ & $85.3 \pm 7.62$ & -0.063 & $86.6 \pm 8.21 \beta$ & $85.8 \pm 8.76$ & 0.094 & $86.3 \pm 7.60 \beta$ & $86.3 \pm 7.82$ & 0.000 \\
\hline Anterolateral & $84.5 \pm 10.4 \mathrm{c}$ & $75.8 \pm 10.7$ & 0.824 & $86.6 \pm 11.8 c$ & $76.4 \pm 10.3$ & 0.921 & $86.1 \pm 10.3 b$ & $77.9 \pm 11.1$ & 0.766 \\
\hline Lateral & $82.9 \pm 15.0 c$ & $68.3 \pm 15.5$ & 0.957 & $86.7 \pm 16.3 c \beta$ & $68.5 \pm 13.3$ & 1.223 & $84.9 \pm 15.3 b$ & $71.0 \pm 17.0$ & 0.860 \\
\hline Posterolateral & $89.2 \pm 10.5$ & $87.3 \pm 12.1$ & 0.168 & $93.5 \pm 12.8$ a $\beta$ & $89.4 \pm 10.9$ & 0.345 & $92.0 \pm 9.58 \beta$ & $89.9 \pm 14.0$ & 0.175 \\
\hline Posterior & $91.3 \pm 10.7$ & $94.3 \pm 11.2$ b & -0.274 & $96.6 \pm 11.4 \%$ \& & $97.2 \pm 11.5 \%$ & -0.052 & $94.6 \pm 10.1 \beta$ & $96.8 \pm 12.5 \mathrm{a}$ & -0.194 \\
\hline Posteromedial & $85.2 \pm 12.4$ & $92.4 \pm 9.73 c$ & -0.646 & $88.9 \pm 11.9 \beta$ & $94.9 \pm 12.3 c$ & -0.496 & $87.3 \pm 12.9$ & $94.1 \pm 10.7$ c & -0.574 \\
\hline Medial & $67.3 \pm 17.4$ & $85.9 \pm 15.0 c$ & -1.145 & $66.9 \pm 19.4$ & $88.1 \pm 17.1 \mathrm{c}$ & -1.159 & $69.8 \pm 18.6$ & $87.4 \pm 15.7 \mathrm{c}$ & -1.023 \\
\hline Anteromedial & $79.5 \pm 11.3$ & $88.8 \pm 10.2 c$ & -0.864 & $80.7 \pm 11.2$ & $89.8 \pm 12.1 c$ & -0.781 & $81.4 \pm 11.8$ & $89.8 \pm 9.48 c$ & -0.785 \\
\hline
\end{tabular}

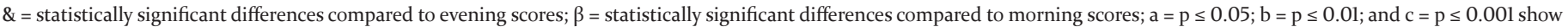
statistically significant differences between dominant and non-dominant legs; ${ }^{\ddagger}=$ the value obtained by dividing each distance by the leg length and multiplying the quotient by 100 ; $\mathrm{ES}=$ effect size. 
Statistically significant differences were found in the average temperatures measured ( $\mathrm{p}<0.001$ ). The lowest body temperature value was found at 9:00, while the highest value was measured at 17:00 (Fig. 2).

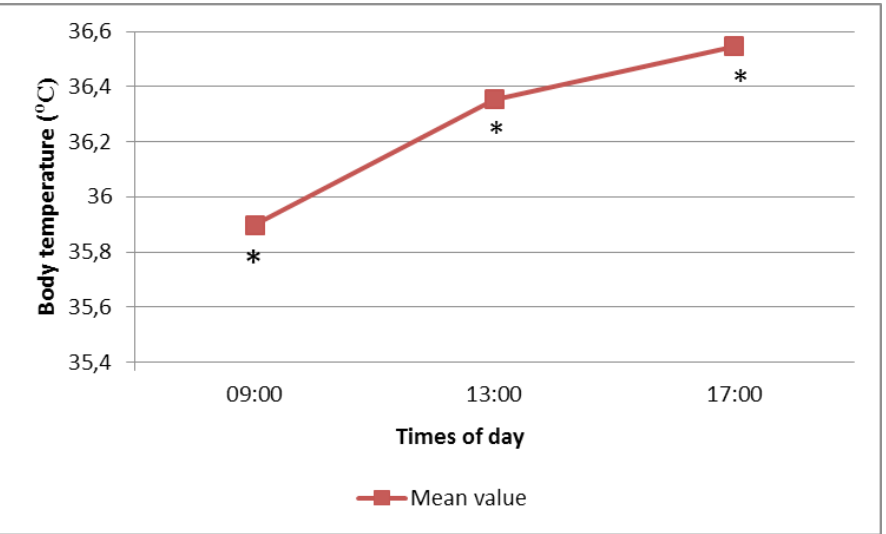

* indicates significant differences with respect to other two time points, $\mathrm{p}<0.001$.

Figure 2. Time-of-day changes in body temperature

A correlation analysis was conducted between the body temperatures and the test performances. A significant positive correlation was found in the body temperature measured at 17:00 and non-dominant leg performance at 9:00 in the anterolateral direction $(\mathrm{r}=0.341, \mathrm{p}=0.027)$, as well as non-dominant leg performance at 13:00 in the anterolateral $(r=0.388, p=$ $0.011)$ and lateral $(\mathrm{r}=0.337, \mathrm{p}=0.029)$ directions. A significant negative correlation was found between the body temperature measured at 13:00 and non-dominant leg performance at 9:00 in the posterior $(\mathrm{r}=-0.319, \mathrm{p}=0.040)$ and posteromedial $(\mathrm{r}=$ $-0.308, \mathrm{p}=0.047$ ) directions.

The SEBT performances of the groups, who were divided into two based on the IPAQ classification, were compared, and a significant difference was found for the 13:00 test scores (for the dominant leg in the anterior, lateral, posterolateral, posterior, and posteromedial directions and for the non-dominant leg in the posterolateral and posterior directions) and for the 17:00 test scores (for the dominant leg in the anterior posterolateral, posterior, and posteromedial directions and for the nondominant leg in the anterior, anterolateral, lateral, and posterolateral directions) compared to the scores of the 9:00 test. When the groups were compared, the trained group was found to score better in posterior directions (posterolateral, posterior, and posteromedial) in the dominant leg in the 13:00 and 17:00 tests (Tab. 3).

The results of the two questionnaires used for sleep state assessment were parallel to each other. The participants' mean score in the Epworth Sleep Scale was found to be 4.92 (normal value), and the mean score obtained with the MorningnessEveningness Questionnaire was $48.8 \pm 7.01$. Six participants were identified as closer to the evening type, and 3 were closer to the morning type. Thirty-three participants were found to be intermediate types. Thus, two groups were created: one group of participants closer to morning or evening types $(n=9)$ and the other one consisting of intermediate types $(n=33)$. The SEBT results of these groups were compared. A significant performance difference was found between the two legs especially in intermediate types, in particular in anterior directions in the

Table 3. Comparison of dominant and non-dominant leg SEBT scores according to time of day in trained $(\mathrm{n}=27)$ and control $(\mathrm{n}=15)$ groups

\begin{tabular}{|c|c|c|c|c|c|c|c|c|c|}
\hline & \multicolumn{2}{|c|}{ 9:00 } & \multirow[b]{2}{*}{ ES } & \multicolumn{2}{|c|}{$13: 00$} & \multirow[b]{2}{*}{ ES } & \multicolumn{2}{|c|}{$17: 00$} & \multirow[b]{2}{*}{ ES } \\
\hline & Trained & Control & & Trained & Control & & Trained & Control & \\
\hline Anterior (D) & $84.7 \pm 9.38$ & $84.9 \pm 5.54$ & -0.026 & $87.7 \pm 9.29 \beta$ & $84.6 \pm 5.52$ & 0.085 & $87.3 \pm 8.18 \beta$ & $84.5 \pm 6.30$ & 0.384 \\
\hline Anterior (ND) & $85.2 \pm 7.43$ & $85.6 \pm 8.22$ & -0.051 & $86.9 \pm 9.59$ & $83.7 \pm 6.87$ & 0.384 & $87.1 \pm 8.49 \beta$ & $84.8 \pm 6.43$ & 0.310 \\
\hline Anterolateral (D) & $85.7 \pm 11.2 \mathrm{c}$ & $82.5 \pm 8.67$ & 0.320 & $88.2 \pm 13.0 \mathrm{c}$ & $83.7 \pm 8.87$ & 0.404 & $87.2 \pm 11.3 c$ & $84.3 \pm 8.49 b$ & 0.290 \\
\hline Anterolateral (ND) & $75.5 \pm 8.41$ & $76.3 \pm 14.3$ & -0.068 & $77.4 \pm 9.11$ & $74.6 \pm 12.4$ & 0.257 & $79.2 \pm 11.5 \beta$ & $75.4 \pm 10.1$ & 0.351 \\
\hline Lateral (D) & $85.0 \pm 15.3 c$ & $79.2 \pm 14.3$ & 0.392 & $89.1 \pm 17.9 \beta \mathrm{c}$ & $82.4 \pm 12.2 \mathrm{a}$ & 0.437 & $86.5 \pm 16.7 c$ & $81.9 \pm 12.4 \mathrm{a}$ & 0.313 \\
\hline Lateral (ND) & $66.8 \pm 12.1$ & $70.9 \pm 20.4$ & -0.245 & $69.7 \pm 12.6$ & $66.4 \pm 14.6$ & 0.242 & $73.1 \pm 17.6 \beta$ & $67.3 \pm 15.9$ & 0.346 \\
\hline Posterolateral (D) & $90.0 \pm 11.0$ & $87.6 \pm 9.79$ & 0.230 & $96.5 \pm 13.7 \beta \mathrm{a}^{*}$ & $88.0 \pm 9.02$ & 0.733 & $95.0 \pm 9.96 \beta^{*}$ & $86.8 \pm 6.20$ & 0.988 \\
\hline Posterolateral (ND) & $87.7 \pm 10.7$ & $86.4 \pm 11.6$ & 0.116 & $91.6 \pm 10.4 \beta$ & $85.5 \pm 11.1$ & 0.567 & $92.9 \pm 13.9 \beta$ & $84.5 \pm 12.8$ & 0.629 \\
\hline Posterior (D) & $91.3 \pm 10.9$ & $91.3 \pm 10.8$ & 0.000 & $99.6 \pm 11.9 \beta^{*}$ & $91.0 \pm 8.26$ & 0.840 & $97.9 \pm 10.0 \beta^{*}$ & $88.7 \pm 7.52$ & 1.040 \\
\hline Posterior (ND) & $95.2 \pm 10.6$ b & $92.6 \pm 12.4$ & 0.225 & $99.5 \pm 12.0 \beta$ & $93.1 \pm 9.49$ & 0.592 & $98.4 \pm 12.4$ & $94.0 \pm 12.7 \mathrm{a}$ & 0.351 \\
\hline Posteromedial (D) & $85.4 \pm 11.4$ & $84.9 \pm 14.3$ & 0.039 & $91.7 \pm 12.0 \beta$ * & $83.8 \pm 10.1$ & 0.712 & $90.7 \pm 12.1 \beta$ * & $81.3 \pm 12.3$ & 0.770 \\
\hline Posteromedial (ND) & $93.3 \pm 10.6 b$ & $90.8 \pm 8.15$ & 0.264 & $96.9 \pm 13.6 \mathrm{~b}$ & $91.4 \pm 8.87 \mathrm{~b}$ & 0.479 & $95.3 \pm 11.9 \mathrm{c}$ & $92.1 \pm 8.22 c$ & 0.313 \\
\hline Medial (D) & $66.2 \pm 16.2$ & $69.4 \pm 19.7$ & -0.177 & $67.4 \pm 20.8$ & $66.1 \pm 17.1$ & 0.068 & $71.4 \pm 19.3$ & $66.9 \pm 17.5$ & 0.244 \\
\hline Medial (ND) & $87.3 \pm 15.0 \mathrm{c}$ & $83.4 \pm 15.2$ & 0.258 & $89.5 \pm 19.0 \mathrm{c}$ & $85.6 \pm 13.3 b$ & 0.238 & $87.9 \pm 16.8 \mathbf{b}$ & $86.5 \pm 13.9 \mathrm{~b}$ & 0.091 \\
\hline Anteromedial (D) & $78.5 \pm 11.3$ & $81.1 \pm 11.5$ & -0.228 & $81.0 \pm 12.1$ & $80.1 \pm 9.70$ & 0.082 & $82.1 \pm 13.2$ & $80.3 \pm 8.93$ & 0.160 \\
\hline Anteromedial (ND) & $89.1 \pm 10.4 \mathrm{c}$ & $88.2 \pm 10.1$ & 0.088 & $90.9 \pm 13.8 c$ & $87.8 \pm 8.21 \mathrm{~b}$ & 0.273 & $90.6 \pm 10.4 b$ & $88.2 \pm 7.79 b$ & 0.261 \\
\hline
\end{tabular}

$\mathrm{D}=$ dominant leg; $\mathrm{ND}=$ non-dominant leg; $\beta=$ shows statistically significant differences compared to morning scores; $\mathrm{a}=\mathrm{p} \leq 0.05 ; \mathrm{b}=\mathrm{p} \leq 0.01 ;$ and $\mathrm{c}=\mathrm{p} \leq 0.001$ show statistically significant differences between dominant and non-dominant legs; * $=$ shows statistically significant differences between trained and control groups; ES = effect size. 
dominant leg (anteromedial, medial, and posteromedial) and in posterior directions (posterior, posterolateral, and posteromedial) in the non-dominant leg. When the test performances of these groups at different times of the day were compared, the intermediate types had significantly higher test scores in the dominant leg in the lateral, posterolateral, and posterior directions at 13:00 in comparison with the scores at 9:00.

The SEBT results were compared on the basis of gender, and men revealed significantly better performance, especially in the 9:00 and 13:00 tests. When the results obtained for the dominant and non-dominant legs were compared, there were significant differences in the dominant leg in the anterolateral and lateral directions and in the non-dominant leg in the posteromedial and medial directions in every session in both genders. When the scores of female participants at three different times of the day were compared, it was found that the scores for the anterolateral, lateral, and posterior directions at 13:00 as well as the anterior, anterolateral, lateral, posterolateral, and posterior directions and the posterior direction for the non-dominant leg at 17:00 differed significantly from the test scores at 9:00. In the male participants, however, the significant differences were noted between the posterolateral, posterior, and posteromedial directions at 13:00 and the posterior and posteromedial directions at 17:00 test scores as well as those at 9:00. Time-dependent balance performance changes in the dominant and nondominant legs showed a similar structure in terms of gender $(\mathrm{p}>0.05)[\mathrm{F}(2,80)=2.081, \mathrm{p}=0.131, \eta \mathrm{p} 2=0.049]$.

\section{Discussion}

The primary purpose of this study was to examine the effect of circadian rhythm on dynamic balance performance, and the secondary purpose was to investigate the influence of physical activity level, body temperature, sleep state, and gender on this possible effect.

Dynamic postural balance has generally been studied using a single-leg hop test [24], stability biodex [15], and the posturography system [25]. These methods assess dynamic postural control functionally but not the stability ability of individuals [26]. SEBT is simple and affordable and requires no professional equipment. It has better validity and reliability than other tests. This test can assess functional abilities, including stability ability and dynamic balance control, based on the performance of the lower body in 8 directions [14, 27, 28].

Circadian rhythm is known to affect many athletic abilities [29]. Some other factors like age, the type and intensity of exercise, jet-lag, and sleeplessness also affect these daily changes $[15,29,30]$.

The number of studies that examine the relation between circadian rhythm and balance is limited. In a study on rhythmic gymnasts, static balance performance was found not to change at any time of the day, and dynamic balance performance was observed to reach a peak in the morning [11]; similarly, dynamic balance performance was reported to be better in the morning [9]. In another study with participants over the age of 65, Jorgensen et al. [31] reported that the most significant negative changes in postural balance were observed at 12:30 and 16:00 based on postural sway area (7.1\%) and postural sway length (4.6\%). In another study with young and healthy participants, the best score related to a dynamic balance test was reached at 9:00, and the worst score was obtained at 13:00 [32]. In a study with young participants, the best SEBT score was reached at 10:00 compared to other scores recorded at different times of the day [23].
In contrast to the results of these studies, Heinbaugh, Smith, Zhu, Wilson, and Dai [33] applied a dynamic balance test (Y Balance Test) to 34 physically active participants at 7:0010:00 and 15:00-18:00. They reported that circadian rhythm had a minimal effect on dynamic balance. In our study, the lowest test scores were observed in the morning, and the highest scores were obtained at 13:00 in the dominant leg $(\mathrm{p} \leq 0.05)$. Sleep state, body temperature, and training level, which are all known to exert possible effects on circadian rhythm, might have played a role in these results.

Different muscles are involved in SEBT performances in different reaching directions. Hamstrings and quadriceps muscles are effective in all directions. The vastus lateralis is generally active in the dynamic balance performance of the non-dominant leg in the medial and posteromedial directions [34]. However, the biceps femoris muscle functions more in the posterior, posterolateral, and lateral directions. In our study, SEBT tests were conducted with the dominant and non-dominant legs at different times of the day. Statistically significant differences were found in the anterior directions in the dominant leg and in the posterior directions in the non-dominant leg. Given that other features that affect SEBT performance are range of motion [21], neuromuscular coordination, and strength [14, 35], trained participants might be expected to reach test scores significantly different from those of untrained ones, and the dominant leg might be expected to reach test scores significantly different from those of the non-dominant one.

In another study on the relation between different $Q$ angles and static and dynamic balance performance, the dominant leg was reported to have a longer reaching distance in SEBT [36]. The fact that the non-dominant leg might have a lower neuromuscular capacity than the dominant leg was thought to be an important factor [37].

The changes in body temperature were previously reported to be among the main factors affecting circadian rhythm [13]. In our study, body temperature was thought to have a circadian rhythm effect on the SEBT results: the lowest body temperature and the lowest test scores were obtained at 9:00, and with a gradually increasing body temperature, the best test scores were recorded at 13:00. A correlation analysis was conducted between the test scores and the body temperatures. A significant positive correlation was found between the body temperature at 17:00 and the results for the non-dominant leg in the anteromedial direction in the morning and the anteromedial and medial directions test at 13:00. A significant negative correlation was found between the body temperature at 13:00 and the results for the non-dominant leg in the posterior and posterolateral directions in the morning ( $\mathrm{p} \leq 0.05)$. Besides, a statistically significant relationship was found between the average temperatures measured and the percentage temperature differences among them (between 9:00 and 17:00, 1.67\%). As in our study, body temperature changes detected in previous studies were $2 \%$ [38], $2.7 \%$ [39], $1 \%$ [40], and $1.7 \%$ [15].

In studies that support the findings of our study, the physical performance of swimmers [41] and cyclists [30, 42] was reported to gradually increase throughout the day, and a positive correlation with body temperature was found. In a study on the comparison of body temperature and jumping score at 10:00 and 17:00, body temperature $\left(36.9\right.$ vs. $\left.37.2^{\circ} \mathrm{C} ; \mathrm{p}<0.001\right)$ and peak power output of jumping ( 5248 vs. $5413 \mathrm{~W} ; \mathrm{p}<0.001)$ were found to increase at 17:00. It was concluded that slight circadian changes in body temperatures might affect the physical performance of elite players [43]. 
Regularly training athletes have a better balance performance. In a study on the dynamic balance performances of elite athlete groups, gymnasts proved to have better balance scores than all other groups. Football players and swimmers were better than individual athletes, and all the athletes had better scores than control groups. However, no significant difference between women and men was reported [44]. In our study, when the participants were grouped as trained (very active) and control (inactive or mildly active), the trained group had significantly better scores at 13:00 and at 17:00 in the posterior directions. These results can be linked to the fact that trained athletes have more muscle strength and a better range of motion as a consequence of regular exercise.

Schlesinger et al. [12] emphasised that complex balance movements require more concentration and attention, and therefore the sleep state of participants is important. In our study, the test performance did not show a difference at different times of the day for either leg in terms of chronotype. This result was thought to be related to the fact that the majority of the group were intermediate types. Likewise, no significant relation was reported between the dynamic balance test scores in non-trained adolescents and body temperature variations by other authors [11].

One of the factors that affect dynamic balance performance is gender [35]. Female participants performed worse than male participants in terms of posterior extensions [23]. This result was linked to the fact that in SEBT tests, the quadriceps muscles are more dominant in anterior extensions, while hamstring muscles are more dominant in posterior extensions. Actually, women usually have stronger quadriceps femoris muscles and weaker hamstring muscles. In our study, men performed significantly better than women in the 9:00 and 13:00 tests. The physical, physiological, and conditional features of male participants were thought to have an effect on this result.

\section{Conclusions}

Our study demonstrated that dynamic balance performance was affected by circadian rhythm with the influences of body temperature, gender, and physical activity level. Chronotype was not found to have an effect on the results in our study.

Further studies that will be conducted on large samples with controlled physical activity will provide more reliable information about balance performance.

\section{Acknowledgements}

The article is a summary of the first author's Master's thesis.

\section{Literature}

1. Can B. (2008). The effect of balance training on the sense of proprioception depending on fatigue in female volleyball players. Doctoral thesis. Gazi University, Institute of Health Sciences, Ankara. [in Turkish]

2. Noakes T. (2000). Physiological models to understand exercise fatigue and the adaptations that predict or enhance athletic performance. Scandinavian Journal of Medicine and Science in Sports 10(3), 123-145.

3. Kor A. (2015). Dynamic techniques for clinical assessment of the athlete. Clinics in Podiatric Medicine and Surgery $32(2), 217-229$.
4. Drust B., Waterhouse J., Atkinson G., Edwards B., Reilly T. (2005). Circadian rhythms in sports performance-an update. Chronobiology International 22(1), 21-44.

5. Bessot N., Nicolas A., Moussay S., Gauthier A., Sesboüé B., Davenne D. (2006). The effect of pedal rate and time of day on the time to exhaustion from high intensity exercise. Chronobiology International 23(5), 1009-1024.

6. Bernard T., Giacomoni M., Gavarry O., Seymat M., Falgairette G. (1997). Time-of-day effects in maximal anaerobic leg exercise. European Journal of Applied Physiology and Occupational Physiology 77(1), 133-138.

7. Reilly T., Atkinson G., Edwards B., Waterhouse J., Farrelly K., Fairhurst E. (2007). Diurnal variation in temperature, mental and physical performance, and tasks specifically related to football (soccer). Chronobiology International 24(3), 507-519.

8. Reilly T., Marshall S. (1991). Circadian rhythms in power output on a swim bench. Journal of Swimming Research 7(2), 11-13.

9. Gribble P.A., Hertel J. (2003). Considerations for normalizing measures of the Star Excursion Balance Test. Measurement in Physical Education and Exercise Science 7(2), 89100.

10. Zouabi A., Quarck G., Martin T., Grespinet M., Gauthier A. (2016). Is there a circadian rhythm of postural control and perception of the vertical? Chronobiology International 33(10), 1320-1330.

11. di Cagno A., Fiorilli G., Iuliano E., Aquino G., Giombini A., Battaglia C. et al. (2014). Time-of-day effects on static and dynamic balance in elite junior athletes and untrained adolescents. International Journal of Sports Science and Coaching 9(4), 615-625.

12. Schlesinger A., Redfern M.S., Dahl R.E., Jennings J.R. (1998). Postural control, attention and sleep deprivation. Neuroreport 9(1), 49-52.

13. Waterhouse J., Drust B., Weinert D., Edwards B., Gregson W., Atkinson G. et al. (2005). The circadian rhythm of core temperature: Origin and some implications for exercise performance. Chronobiology International 22(2), 207-225.

14. Baghbani F., Woodhouse L.J., Gaeini A.A. (2016). Dynamic postural control in female athletes and nonathletes after a whole-body fatigue protocol. The Journal of Strength and Conditioning Research 30(7), 1942-1947.

15. Isler A. (2005). Investigation of circadian changes in anaerobic performance. Hacettepe Journal of Sports Sciences 16(4), 174-184. [in Turkish]

16. Ozturk M. (2005). The determination of validity and reliability of the International physical activity questionnaire and the physical activity level in university students. Master's thesis. Hacettepe University, Institute of Health Sciences, Ankara. [in Turkish]

17. Horne J.A., Ostberg O. (1975). A self-assessment questionnaire to determine morningness-eveningness in human circadian rhythms. International Journal of Chronobiology 4(2), 97-110.

18. Punduk Z., Gur H., Ercan I. (2005). Reliability of Turkish the morning and evening type questionnaire. Türk Psikiyatri Dergisi 16(1), 40-45. [in Turkish]

19. Izci B., Ardic S., Firat H., Sahin A., Altinors M., Karacan I. (2008). Reliability and validity studies of the Turkish version of the Epworth Sleepiness Scale. Sleep and Breathing $12(2), 161-168$.

20. Sabin M.J. (2011). Reliability and validity of the ConditionModified Star Excursion Balance Test: Influence of concus- 
sion history. Champaign, Illinois: University of Illinois at Urbana-Champaign.

21. Robinson R.H., Gribble P.A. (2008). Support for a reduction in the number of trials needed for the star excursion balance test. Archives of Physical Medicine and Rehabilitation 89(2), 364-370.

22. Gribble P.A., Hertel J., Denegar C.R., Buckley W.E. (2004). The effects of fatigue and chronic ankle instability on dynamic postural control. Journal of Athletic Training 39(4), 321-329.

23. Gribble P.A., Tucker W.S., White P.A. (2007). Time-of-day influences on static and dynamic postural control. Journal of Athletic Training 42(1), 35-41.

24. Riemann B.L., Caggiano N.A., Lephart S.M. (1999). Examination of a clinical method of assessing postural control during a functional performance task. Journal of Sport Rehabilitation 8(3), 171-183.

25. Zemková E., Viitasalo J., Hannola H., Blomqvist M., Konttinen N., Mononen K. (2007). The effect of maximal exercise on static and dynamic balance in athletes and nonathletes. Medicina Sportiva 11(3), 70-77.

26. Arnold B.L., Schmitz R.J. (1998). Examination of balance measures produced by the Biodex Stability System. Journal of Athletic Training 33(4), 323-327.

27. Kinzey S.J., Armstrong C.W. (1998). The reliability of the star-excursion test in assessing dynamic balance. Journal of Orthopaedic and Sports Physical Therapy 27(5), 356-360.

28. Seliga R., Bhattacharya A., Succop P., Wickstrom R., Smith D., Willeke K. (1991). Effect of work load and respirator wear on postural stability, heart rate, and perceived exertion. The American Industrial Hygiene Association Journal 52(10), 417-422.

29. Reilly T., Atkinson G., Waterhouse J. (2000). Chronobiology and physical performance. Exercise and Sport Science 24, 351-372.

30. Atkinson G., Todd C., Reilly T., Waterhouse J. (2005). Diurnal variation in cycling performance: Influence of warm-up. Journal of Sports Sciences 23(3), 321-329.

31. Jorgensen M., Rathleff M.S., Laessoe U., Caserotti P., Nielsen O., Aagaard P. (2012). Time-of-day influences postural balance in older adults. Gait and Posture 35(4), 653657.

32. Kwon Y.H., Choi Y.W., Nam S.H., Lee M.H. (2014). The influence of time of day on static and dynamic postural control in normal adults. Journal of Physical Therapy Science 26(3), 409-412.
33. Heinbaugh E.M., Smith D.T., Zhu Q., Wilson M.A., Dai B. (2015). The effect of time-of-day on static and dynamic balance in recreational athletes. Sports Biomechanics 14(3), 361-373.

34. Erkmen N., Taşkın H., Kaplan T., Sanioglu A. (2009). The effect of fatiguing exercise on balance performance as measured by the balance error scoring system. Isokinetics and Exercise Science 17(2), 121-127.

35. Plisky P.J., Rauh M.J., Kaminski T.W., Underwood F.B. (2006). Star Excursion Balance Test as a predictor of lower extremity injury in high school basketball players. Journal of Orthopaedic and Sports Physical Therapy 36(12), 911-919.

36. Denizoglu H. (2010). Correlation between $Q$ angle and balance in healthy individuals. Master's thesis. Abant Izzet Baysal University, Institute of Health Sciences, Burdur. [in Turkish]

37. Stelmach G.E., Worringham C.J., Strand E.A. (1987). The programming and execution of movement sequences in Parkinson's disease. International Journal of Neuroscience 36(1-2), 55-65.

38. Hill D., Smith J. (1991). Circadian rhythm in anaerobic power and capacity. Canadian Journal of Sport Sciences 16(1), 30-32.

39. Melhim A.F. (1993). Investigation of circadian rhythms in peak power and mean power of female physical education students. International Journal of Sports Medicine 14(6), 303-306.

40. Sekir U., Ozyener F., Gur H. (2002). Effect of time of day on the relationship between lactate and ventilatory thresholds: A brief report. Journal of Sports Science and Medicine 1(4), 136-140.

41. Martin L., Thompson K. (2000). Reproducibility of diurnal variation in sub-maximal swimming. International Journal of Sports Medicine 21(06), 387-392.

42. Edwards B., Edwards W., Waterhouse J., Atkinson G., Reilly T. (2005). Can cycling performance in an early morning, laboratory-based cycle time-trial be improved by morning exercise the day before? International Journal of Sports Medicine 26(08), 651-656.

43. West D.J., Cook C.J., Beaven M.C., Kilduff L.P. (2014). The influence of the time of day on core temperature and lower body power output in elite rugby union sevens players. The Journal of Strength and Conditioning Research 28(6), 15241528.

44. Davlin C.D. (2004). Dynamic balance in high level athletes. Perceptual and Motor Skills 98(3 Suppl.), 1171-1176.

Submitted: May 8, 2017

Accepted: June 30, 2017 